\title{
EDUCAÇÃO DO CAMPO: NOTAS PARA UMA ANÁLISE DE PERCURSO
}

\author{
FIELD EDUCATION: NOTES FOR AN ANALYSIS OF THE COURSE
}

Roseli Salete Caldart ${ }^{1}$

Resumo Este ensaio busca contribuir na construção de uma chave metodológica para interpretação do percurso e da situação atual da educação do campo, um fenômeno recente da realidade educacional brasileira, que tem os movimentos sociais camponeses como principais protagonistas. O texto inicia com uma análise da constituição originária da Educação do campo, identificando contexto, práticas e sujeitos. Em seguida, discute as tensões e contradições principais do seu percurso, especialmente as que se produzem na relação entre movimentos sociais e Estado, na afirmação de uma tradição pedagógica emancipatória e da luta por políticas públicas que garantam o acesso dos camponeses à educação escolar em seu próprio território. Por fim, são identificados alguns impasses e desafios principais da Educação do campo na atualidade, relacionando-os ao momento atual de crise mundial do capitalismo e como ela se materializa nas questões relacionadas ao trabalho do campo.

Palavras-chave campo; trabalho; educação; movimentos sociais; política pública.
Abstract This essay seeks to contribute to building a methodological key to interpret the course and the current status of field education, a recent phenomenon in the Brazilian educational reality which has peasant social movements as its main actors. The article begins with an analysis of the original Field Education constitution, identifying its context, practices, and subjects. It then discusses the main tensions and contradictions in its course, particularly those that are produced in the relationship between the social movements and the State, in the affirmation of an emancipatory pedagogic tradition, and in the struggle for public policies that ensure peasant access to formal school education in their own territory. Finally, a few of the impasses and challenges that were singled out regarding the modern day Field education, relating them to the current global crisis of capitalism and to how it materializes itself in the issues related to work in the field.

Keywords field; work; education; social movements; public policy. 
O sentido do nosso movimento não é anterior à
nossa intervenção: é instaurado por nós, dentro
dos limites que nos são impostos pelo quadro
em que nos inserimos.

(Leandro Konder, 2003)

Discutir sobre a Educação do campo hoje, e buscando ser fiel aos seus objetivos de origem, nos exige um olhar de totalidade, em perspectiva, com uma preocupação metodológica, sobre como interpretá-la, combinada a uma preocupação política, de balanço do percurso e de compreensão das tendências de futuro para poder atuar sobre elas.

É momento de perguntar, passados dez anos deste 'batismo', que objeto de estudo, de práticas, de política é este que atende pelo nome de 'Educação do campo'? Tratamos de que realidade e em que contexto ou sobre 'que movimento e em que quadro'? Por que a Educação do campo já se configura como um fenômeno da realidade brasileira que exige tomada de posição, prática e teórica? Por que tem causado desconforto em segmentos politicamente diferentes ou mesmo contrapostos? Qual o movimento do real provocado ou expresso pela Educação do campo que incomoda e já instiga debates sobre sua significação: que tipo de práticas e de políticas podem mesmo ser designadas como tal? Por que Educação do campo e não Educação rural? E, afinal, qual o balanço deste movimento da realidade? E qual o significado histórico que já é possível apreender da emergência da Educação do campo no contexto da educação brasileira contemporânea e das lutas dos trabalhadores, do campo e da cidade, por uma educação emancipatória e, mais amplamente, pela superação das relações sociais capitalistas?

Sem dúvida nossa retrovisão histórica é ainda muito pequena para dar conta de uma análise mais profunda do processo de construção práticoteórica da Educação do campo. Mas a necessidade de tomada de posição imediata e de um pensamento que ajude a orientar uma intervenção política na realidade de que trata nos exige pelo menos uma aproximação analítica nesta perspectiva. Vivemos em um tempo de urgências: densas e radicais como são as questões da vida concreta, de pessoas concretas, especialmente as questões de 'vida por um fio', nos seus vários sentidos. E não estamos fazendo esta discussão sobre o percurso da Educação do campo em um momento qualquer, mas exatamente no momento onde estas urgências eclodem em um cenário de crise estrutural da sociedade capitalista, o que se de um lado dificulta ainda mais uma análise objetiva, de outro nos instiga a balanços projetivos que possam ajudar a reorganizar nossa atuação política diante de velhos e novos cenários. ${ }^{2}$

Podemos dizer sobre a Educação do campo, parafraseando Emir Sader (prefácio a Mészáros, 2005, p. 15) que sua natureza e seu destino estão 
profundamente ligados ao destino do trabalho no campo e, consequentemente, ao destino das lutas sociais dos trabalhadores e da solução dos embates de projetos que constituem a dinâmica atual do campo brasileiro, da sociedade brasileira, do mundo sob a égide do capitalismo em que vivemos. E ainda que 'muitos não queiram', esta realidade exige posição (teórica sim, mas sobretudo prática, política) de todos os que hoje afirmam trabalhar em nome da Educação do campo.

Busco desenvolver este texto 3 na perspectiva de construção de uma chave metodológica para interpretação do percurso e da situação atual da Educação do campo, orientando-me por dois pressupostos teóricos bem antigos, do nosso velho camarada Marx: o primeiro é o de buscar compreender o 'movimento' e os 'aspectos contraditórios' do real, muito mais do que afirmar e repetir obstinadamente princípios abstratos (Lefebvre, 1981), o que me parece ainda mais importante se o que pretendemos é justamente tomar posição diante de questões relacionadas à transformação da realidade. E o segundo é o da crítica como perspectiva metodológica ou como guia da interpretação teórica. Crítica aqui não no sentido simplificado de denúncia de uma determinada situação, mas sim de leitura rigorosa do atual estado de coisas, ou do movimento real de sua transformação. 4

O momento me parece propício para retomada destes pressupostos, tanto pelo embate geral de ideias ou de referenciais de interpretação da realidade que tende a ficar mais forte neste período de crise, como pela particularidade da situação atual da Educação do campo. Há hoje uma diversidade de sujeitos sociais que se colocam como protagonistas da Educação do campo, nem sempre orientados pelos mesmos objetivos e por concepções consonantes de educação e de campo, o que exige uma análise mais rigorosa dos rumos que estas ações sinalizam.

De outro lado, começam a surgir, especialmente no mundo acadêmico, algumas interpretações sobre o fenômeno da Educação do campo, que têm ficado excessivamente centradas nos discursos de determinados sujeitos, priorizando a discussão lógica do uso ou da ausência de conceitos ou de categorias teóricas, buscando identificar as contradições no plano das ideias ou, ainda mais restritamente, no plano dos textos produzidos com esta identificação de Educação do campo. Estes exercícios analíticos são importantes, desde que não se descolem da materialidade objetiva dos sujeitos, humanos e coletivos, que constituíram e fazem no dia a dia a luta pela educação da classe trabalhadora do campo. Existem sim tensões de concepções teóricas entre os sujeitos hoje envolvidos com a Educação do campo e é importante apreendê-las, discuti-las, mas não podemos perder de vista que os parâmetros do debate das ideias devem ser dados pela análise do movimento da realidade concreta, sob pena de não participarem dele ou, pior, ajudarem 
a fortalecer posições políticas conservadoras, sobre o campo e sobre a educação dos trabalhadores.

Em síntese o que gostaria de defender/reafirmar é a necessidade e a importância, política, teórica, de compreender este fenômeno chamado de Educação do campo em sua historicidade, o que implica buscar apreender as contradições e tensões que estão na realidade que a produziu e que a move, e que ela ajuda a produzir e mover; que estão no 'estado da coisa', afinal, e não apenas nas ideias ou entre ideias sobre o que dela se diz.

Entendo que uma das características constitutivas da Educação do campo é a de se mover desde o início sobre um 'fio de navalha', que somente se consegue compreender pela análise das contradições reais em que está envolvida e que, nunca é demais repetir, não são as contradições do território estrito da pedagogia, mas da luta de classes, particularmente de como se desenvolve hoje no campo brasileiro, em todas as dimensões de sua realidade.

Este 'fio de navalha' precisa ser analisado, pois, no terreno das tensões e contradições e não das antinomias, estas últimas muito mais próprias ao mundo das ideias do que ao plano da realidade concreta, das lutas pela vida real em uma sociedade como a nossa: sim! A Educação do campo toma posição, age, desde uma particularidade e não abandona a perspectiva da universalidade, mas disputa sua inclusão nela (seja na discussão da educação ou de projeto de sociedade). Sim! Ela nasce da 'experiência de classe' de camponeses organizados em movimentos sociais e envolve diferentes sujeitos, às vezes com diferentes posições de classe. Sim! A Educação do campo inicia sua atuação desde a radicalidade pedagógica destes movimentos sociais e entra no terreno movediço das políticas públicas, da relação com um Estado comprometido com um projeto de sociedade que ela combate, se coerente for com sua materialidade e vínculo de classe de origem. Sim! A Educação do campo tem se centrado na escola e luta para que a concepção de educação que oriente suas práticas se descentre da escola, não fique refém de sua lógica constitutiva, exatamente para poder ir bem além dela enquanto projeto educativo. E uma vez mais, sim! A Educação do campo se coloca em luta pelo acesso dos trabalhadores ao conhecimento produzido na sociedade e ao mesmo tempo problematiza, faz a crítica ao modo de conhecimento dominante e à hierarquização epistemológica própria desta sociedade que deslegitima os protagonistas originários da Educação do campo como produtores de conhecimento e que resiste a construir referências próprias para a solução de problemas de uma outra lógica de produção e de trabalho que não seja a do trabalho produtivo para o capital.

Neste texto, busco exercitar essa perspectiva metodológica de compreender o movimento real da Educação do campo, discutindo-o através de três questões que me parecem importantes na constituição dessa análise, 
ainda que aqui as aborde sem a pretensão de esgotá-las nem de já estar dando-lhes o tratamento teórico necessário. A primeira diz respeito à constituição originária, material, prática da Educação do campo. A segunda trata de apreender algumas tensões e contradições principais do seu percurso. A terceira, pensando que é preciso incidir nos rumos da ação política com a urgência que nosso tempo nos coloca, se relaciona ao esforço de identificar alguns impasses e desafios do momento atual da Educação do campo.

Na sequência, algumas notas sobre cada uma das três questões, no intuito principal de provocar um debate que nos dê indicações para uma construção mais coletiva desta chave de leitura.

\section{Sobre a constituição originária da Educação do campo}

Ainda não fizemos uma narrativa escrita e refletida dessa história com mais rigor de detalhes (desafio de pesquisa). Há registros esparsos, fragmentados. E já há versões que alteram seus sujeitos principais, deslocando o protagonismo dos movimentos sociais, dos camponeses, colocando a Educação do campo como um continuum do que na história da educação brasileira se entende por educação rural ou para o meio rural. Nestas notas, destaco algumas ideias-força para nosso debate de interpretação da constituição de origem da Educação do campo. ${ }^{5}$

\section{A Educação do campo como crítica}

A Educação do campo nasceu como crítica à realidade da educação brasileira, particularmente à situação educacional do povo brasileiro que trabalha e vive no/do campo.

Esta crítica nunca foi à educação em si mesma porque seu objeto é a realidade dos trabalhadores do campo, o que necessariamente a remete ao trabalho e ao embate entre projetos de campo que têm consequências sobre a realidade educacional e o projeto de país. Ou seja, precisamos considerar na análise que há uma perspectiva de totalidade na constituição originária da Educação do campo.

E tratou-se primeiro de uma crítica prática: lutas sociais pelo direito à educação, configuradas desde a realidade da luta pela terra, pelo trabalho, pela igualdade social, por condições de uma vida digna de seres humanos no lugar em que ela aconteça. É fundamental considerar para compreensão da constituição histórica da Educação do campo o seu vínculo de origem com as lutas por educação nas áreas de reforma agrária ${ }^{6}$ e como, especialmente neste vínculo, a Educação do campo não nasceu como uma crítica 
apenas de denúncia: já surgiu como contraponto de práticas, construção de alternativas, de políticas, ou seja, como crítica projetiva de transformações.

Uma crítica prática que se fez teórica ou se constituiu também como confronto de ideias, de concepções, quando pelo 'batismo' (nome) assumiu o contraponto: Educação do campo não é Educação rural, com todas as implicações e desdobramentos disso em relação a paradigmas que não dizem respeito e nem se definem somente no âmbito da educação. ${ }^{7}$

A Educação do campo surgiu em um determinado momento e contexto histórico e não pode ser compreendida em si mesma, ou apenas desde o mundo da educação ou desde os parâmetros teóricos da pedagogia. Ela é um movimento real de combate ao 'atual estado de coisas': movimento prático, de objetivos ou fins práticos, de ferramentas práticas, que expressa e produz concepções teóricas, críticas a determinadas visões de educação, de política de educação, de projetos de campo e de país, mas que são interpretações da realidade construídas em vista de orientar ações/lutas concretas.

É então desde esse parâmetro que a Educação do campo deve ser analisada e não como se fosse um ideal ou um ideário político-pedagógico a ser implantado ou ao qual a realidade da educação deve se sujeitar. Talvez isso incomode a alguns: a Educação do campo não é uma proposta de educação. Mas enquanto crítica da educação em uma realidade historicamente determinada ela afirma e luta por uma concepção de educação (e de campo).

Para analisar um fenômeno que se constitui como uma crítica material a um determinado estado de coisas, nada mais próprio, pois, do que buscarmos construir uma crítica de perspectiva materialista, 8 o que inclui uma exigência de análise objetiva: qual o balanço crítico que fazemos da realidade educacional das famílias trabalhadoras do campo, passados dez anos deste movimento de lutas e de práticas de Educação do campo? Esta análise pode também ser desdobrada nas questões específicas sobre as quais a crítica da Educação do campo tem se voltado: que crítica tem sido afirmada no debate da Educação do campo sobre a formação de educadores, sobre a educação profissional, sobre o desenho pedagógico das escolas do campo, sobre os objetivos e conteúdos da educação dos camponeses...? Até que ponto as questões da realidade da educação dos camponeses, dos trabalhadores do campo, têm efetivamente pautado o debate da Educação do campo entre seus principais sujeitos: movimentos sociais, governos e instituições educacionais (especialmente as universidades)?

\section{Os movimentos sociais como protagonistas da Educação do campo}

Os protagonistas do processo de criação da Educação do campo são os 'movimentos sociais camponeses em estado de luta', com destaque aos 
movimentos sociais de luta pela reforma agrária e particularmente ao MST.

O vínculo de origem da Educação do campo é com os trabalhadores 'pobres do campo', trabalhadores sem-terra, sem trabalho, mas primeiro com aqueles já dispostos a reagir, a lutar, a se organizar contra 'o estado da coisa', para aos poucos buscar ampliar o olhar para o conjunto dos trabalhadores do campo.

Talvez esta seja a marca mais incômoda da Educação do campo (inclusive para certas ortodoxias de esquerda) e sua grande novidade histórica: os sujeitos que põe em cena como construtores de uma política de educação e de uma reflexão pedagógica. É como se ouvíssemos de diferentes lugares políticos interpelações como as seguintes (ainda que nem sempre ditas nestes termos):

"Como assim desgarrados da terra", "como assim levantados do chão"9 exigindo direitos, cobrando políticas específicas, discutindo educação, produzindo conhecimento? Puxando a frente das lutas, buscando transformação social? Então os camponeses também querem estudar? E pretendem conceber sua escola, seus cursos? Discutir com professores de universidade?

"Só podem ser baderneiros, bandidos, terroristas..."

“Mas alguém já não disse que camponeses são sempre reacionários e não são capazes de se organizar e agir como classe?"

“E o proletariado, a classe operária, os partidos políticos que deveriam lhes dar direção? Como ousam agir politicamente em nome da classe trabalhadora?"

Talvez seja este protagonismo que o percurso da Educação do campo, feito desde as condições objetivas do desenvolvimento histórico concreto, questiona/tensiona e que tantos buscam deslocar, ainda que com objetivos em tese politicamente contrários: deslocar dos movimentos sociais, dos trabalhadores, dos camponeses, dos oprimidos...

Na sua origem, o 'do' da Educação do campo tem a ver com esse protagonismo: não é 'para' e nem mesmo 'com': é dos trabalhadores, educação do campo, dos camponeses, pedagogia do oprimido... Um 'do' que não é dado, mas que precisa ser construído pelo processo de formação dos sujeitos coletivos, sujeitos que lutam para tomar parte da dinâmica social, para se constituir como sujeitos políticos, capazes de influir na agenda política da sociedade. Mas que representa, nos limites 'impostos pelo quadro em que se insere', a emergência efetiva de novos educadores, interrogadores da educação, da sociedade, construtores (pela luta/pressão) de políticas, pensadores da pedagogia, sujeitos de práticas.

Do ponto de vista metodológico e de balanço político, é importante não perder a questão que nos pode ajudar numa análise em perspectiva: o que 
já houve de semelhante na história da educação brasileira e o que isso projeta em relação às tendências da educação do futuro? E para a análise do momento atual é preciso perguntar sobre as tendências de avanço ou de recuo do protagonismo dos movimentos sociais no mover-se da Educação do campo hoje.

\section{A Educação do campo continua uma tradição pedagógica emancipatória}

A Educação do campo, fundamentalmente pela práxis pedagógica dos movimentos sociais, continua e pode ajudar a revigorar a tradição de uma educação emancipatória, retomando questões antigas e formulando novas interrogações à política educacional e à teoria pedagógica. E faz isso, digase novamente, menos pelos ideais pedagógicos difundidos pelos seus diferentes sujeitos e mais pelas tensões/contradições que explicita/enfrenta no seu movimento de crítica material ao atual estado de coisas.

A Educação do campo retoma a discussão e a prática de dimensões ou matrizes de formação humana que historicamente constituíram as bases, os pilares da pedagogia moderna mais radicalmente emancipatória, de base socialista e popular e de referencial teórico marxista, trazendo de volta o sentido de uma "modernidade da libertação" (Wallerstein, 2002, p. 133-50). Refiro-me como pilares ao vínculo entre educação e trabalho (não como 'preparação para' da pedagogia liberal, mas como 'formação desde' da pedagogia socialista), à centralidade dada à relação entre educação e produção ("nos mesmos processos que produzimos nos produzimos como ser humano"), ao vínculo entre educação e cultura, educação e valores éticos; entre conhecimento e emancipação intelectual, social, política (conscientização). Trata-se, afinal, de recolocar para discussão da pedagogia a concepção da práxis como princípio educativo, no sentido de constituidora fundamental do ser humano (Marx).

E esta retomada vem exatamente da exigência do pensar a especificidade: considerar a realidade do campo na construção de políticas públicas e de pedagogia significa considerar os sujeitos da educação e considerar a prática social que forma estes sujeitos como seres humanos e como sujeitos coletivos. E não pretender que a educação/a pedagogia valha e se explique por e em si mesma.

Uma retomada que é também a recuperação de uma visão mais alargada de educação, algo que já aparece como tendência de muitas práticas e reflexões neste novo século: não confundir educação com escola nem absolutizar a educação escolar, como fez no discurso a pedagogia moderna liberal, para que o capital pudesse 'educar' mais livremente as pessoas em outras esferas (uma armadilha em que muitos pedagogos de esquerda também 
caíram). É preciso pensar a escola sim, e com prioridade, mas sempre em perspectiva, para que se possa transformá-la profundamente, na direção de um projeto educativo vinculado a práticas sociais emancipatórias mais radicais. 10

Parece, aliás, que essa relação da Educação do campo com a escola incomoda a alguns: nasceu lutando por escolas e escolas públicas (através do MST fazendo a luta por escolas nos acampamentos e assentamentos), continua centrada nisso, e ao mesmo tempo nasceu, desde a radicalidade da Pedagogia dos Movimentos Sociais, afirmando que educação é mais do que escola..., vinculando-se a lutas sociais por uma humanização mais plena: luta pela terra, pelo trabalho, pela desalienação do trabalho, a favor da democratização do acesso à cultura e à sua produção, pela participação política, pela defesa do meio ambiente.

Desde os movimentos sociais a Educação do campo nasceu trazendo novas (e velhas) interrogações à política educacional e à teoria pedagógica próprias dos tempos 'modernos' (isso também incomoda a uns quantos).

Do ponto de vista da política de acesso à educação talvez o que mais incomode é a ideia do direito coletivo versus a ideia liberal do direito individual. É só pensar na reação que hoje se manifesta em relação às turmas do Pronerall em diversos setores da sociedade. O coletivo pressiona mais o sistema e sendo este coletivo originário dos pobres do campo volta a reação: 'Como assim?' E o direito coletivo interroga com mais força o conteúdo das políticas e da própria educação. Não é qualquer acesso. Não é qualquer formação. Ou seja, a Educação do campo, ao tratar de uma especificidade, e pelo jeito de fazê-lo, configura-se como uma crítica à forma e ao conteúdo do que se entende ser uma política pública e ao modo de construí-la em uma sociedade cindida socialmente como a nossa.

Do ponto de vista da teoria pedagógica há interrogações importantes que merecem ser aqui ao menos brevemente indicadas:

- Os movimentos sociais trouxeram a discussão sobre a sua dimensão educativa. Os movimentos sociais camponeses vêm formulando a reflexão sobre uma 'Pedagogia do Movimento',12 afirmando a luta social e a organização coletiva (constituidoras do movimento social) como matrizes formadoras. Essa formulação em boa medida já está em Marx na sua concepção de práxis ao mesmo tempo como produção e transformação do mundo (que tem no trabalho sua centralidade, mas que vai além dele), porém não tinha sido desdobrada/elaborada pela área da pedagogia (que se centrou mais na reflexão sobre o trabalho e a cultura), a não ser indiretamente, com outra nuance, em Paulo Freire, na sua Pedagogia do Oprimido. ${ }^{13}$ Que implicações esta experiência formativa de quem participa de movimentos sociais traz no pensar uma pedagogia emancipatória e com objetivos de formar os sujeitos da transformação social? Que lições de pedagogia é possível apreender da 
vivência em processos de luta social e organização coletiva para diferentes práticas pedagógicas, inclusive aquelas desenvolvidas na escola?

- O vínculo entre educação e trabalho, central na concepção de uma educação emancipatória, e na própria concepção da práxis como princípio educativo, quando se desdobrou na reflexão específica sobre uma pedagogia do trabalho, teve como objeto central de reflexão teórica o trabalho na sua forma urbano-industrial (Gramsci, Makarenko, Pistrak). Da mesma forma hoje, quando se reflete sobre integração entre educação básica e formação específica para o trabalho, o olhar se coloca para a lógica do trabalho que predomina nas cidades. A Educação do campo, ao retomar esta reflexão sobre a relação entre educação e trabalho, se pergunta e interroga a teoria pedagógica: o que significa pensar a relação educação e trabalho, e fundamentalmente os processos de formação humana ou de produção do ser humano, tendo por base os processos produtivos e as formas de trabalho próprias do campo? Qual a potencialidade formadora e deformadora das diferentes formas de trabalho desenvolvidas atualmente pelos trabalhadores do campo? E que conhecimentos são produzidos por estes trabalhadores (e são deles exigidos no trabalho) que se subordinam à lógica da agricultura industrial e de negócio e, no contraponto, por aqueles que hoje assumem o desafio de reconstrução prática de uma outra lógica de agricultura, a agricultura camponesa do século XXI, que tenha como princípios organizadores a soberania alimentar, o direito dos povos às sementes e à água, a agroecologia, a cooperação agrícola? No âmbito específico da discussão sobre formação profissional, por exemplo, pensar na lógica da agricultura camponesa não é pensar em um trabalho assalariado, que é a forma desde a qual se pensa hoje, inclusive do ponto de vista crítico (nos debates do médio integrado desde a concepção da politecnia), a questão da formação dos trabalhadores para sua inserção nos processos produtivos.

- Na reafirmação da importância da democratização do conhecimento, do acesso da classe trabalhadora ao conhecimento 'historicamente acumulado', ou produzido na luta de classes, a Educação do campo traz junto uma problematização mais radical sobre o próprio modo de produção do conhecimento, como crítica ao mito da ciência moderna, ao cognitivismo, à racionalidade burguesa insensata; como exigência de um vínculo mais orgânico entre conhecimento e valores, conhecimento e totalidade do processo formativo. A democratização exigida, pois, não é somente do acesso, mas também da produção do conhecimento, implicando outras lógicas de produção e superando a visão hierarquizada do conhecimento própria da modernidade capitalista. As questões hoje da construção de um novo projeto/ modelo de agricultura, por exemplo, não implicam somente o acesso dos trabalhadores do campo a uma ciência e a tecnologias já existentes. Exatamente porque elas não são neutras. Foram produzidas desde uma determi- 
nada lógica, que é a da reprodução do capital e não a do trabalho. Esta ciência e estas tecnologias não devem ser ignoradas, mas precisam ser superadas, o que requer uma outra lógica de pensamento, de produção do conhecimento. No caso do desafio atual em relação à agricultura camponesa, efetivamente não se trata de 'extensão', mas de 'comunicação' (Freire, 2001) com e entre os camponeses para produzir o conhecimento necessário.

Esta compreensão sobre a necessidade de um 'diálogo de saberes' está em um plano bem mais complexo do que afirmar a valorização do saber popular, pelo menos na discussão simplificada que predomina em meios educacionais e que na escola se reduz por vezes a um artifício didático vazio. O que precisa ser aprofundado é a compreensão da teia de tensões envolvida na produção de diferentes saberes, nos paradigmas de produção do conhecimento. E do ponto de vista metodológico isso tem a ver com uma reflexão necessária sobre o trabalho pedagógico que valorize a experiência dos sujeitos (Thompson) ${ }^{14}$ e que ajude na reapropriação (teórica) do conhecimento (coletivo) que produzem através dela, colocando-se na perspectiva de superação da contradição entre trabalho manual e trabalho intelectual, que é própria do modo de organização da produção capitalista.

Alguns intelectuais têm alertado para o risco desta reflexão cair em uma espécie de relativização do conhecimento ou da luta histórica da classe trabalhadora pelo acesso à ciência, ao conhecimento que ajuda a produzir pelo seu trabalho, mas do qual é alienado. Há sim este risco de se cair numa postura relativista, embora hoje bem mais presente em determinados posicionamentos intelectuais do que nas práticas e lutas concretas dos trabalhadores. Porém, é preciso perguntar se negar a contradição produzida pelo capitalismo no modo de produção do conhecimento, que absolutizou a ciência ou a racionalidade científica, ou uma forma dela, ao mesmo tempo em que a fez refém de uma lógica instrumental a serviço da reprodução do capital e definiu mecanismos de alienação do trabalhador em relação ao próprio conhecimento que produz pelo seu trabalho, não é um risco ainda maior para nossos objetivos de superação do capitalismo.

Do ponto de vista de um balanço projetivo da Educação do campo nesta questão específica da tradição pedagógica que assumiu continuar, é preciso perguntar até que ponto esta mensagem está chegando aos educadores e às educadoras do campo e se estas novas interrogações estão entrando em alguma medida na agenda da elaboração teórica e do debate pedagógico da educação dos trabalhadores de nosso tempo. 


\section{Afirmação das Escolas do campo}

Uma questão específica colocada pela Educação do campo tanto à política educacional como à teoria pedagógica diz respeito à concepção de escola e à discussão sobre uma 'escola do campo'.

Novamente escutemos uma interpelação frequente: como assim uma 'escola do campo'? Então a escola não é escola em qualquer lugar, em qualquer tempo, seja para quem for? E por que nunca se fala de uma 'escola da cidade'? Por acaso a Educação do campo defende um tipo de escola diferente para as famílias dos trabalhadores do campo? E nosso debate histórico sobre a escola unitária onde fica?

Não. A crítica originária da Educação do campo à escola (ou à ausência dela) nunca defendeu um tipo específico de escola para os trabalhadores do campo. Sua crítica veio em dois sentidos: sim, a escola deve estar em todos os lugares, em todos os tempos da vida, para todas as pessoas. O campo é um lugar, seus trabalhadores também têm direito de ter a escola em seu próprio lugar e a ser respeitados quando nela entram e não expulsos dela pelo que são... Como lugar de educação, a escola não pode trabalhar 'em tese': como instituição cuja forma e conteúdo valem em si mesmos, em qualquer tempo e lugar, com qualquer pessoa, desenvolvendo uma 'educação' a-histórica, despolitizada (ou falsamente despolitizada), asséptica...

O 'do campo', neste caso, retoma a velha discussão sobre como fazer uma escola vinculada à 'vida real', não no sentido de apenas colada a necessidades e interesses de um cotidiano linear e de superfície, mas como síntese de múltiplas relações, determinações, como questões da realidade concreta. Retoma a interrogação sobre a necessidade/possibilidade de vínculo da escola, de seu projeto pedagógico, com sujeitos concretos na diversidade de questões que a 'vida real' lhes impõe. Uma escola cujos profissionais sejam capazes de coordenar a construção de um currículo que contemple diferentes dimensões formativas e que articule o trabalho pedagógico na dimensão do conhecimento com práticas de trabalho, cultura, luta social.15

Trata-se de uma reflexão que pode nos ajudar a relembrar que continuamos, sim, defendendo e lutando pela escola unitária, mas que o unitário não pode ser um falso universalismo (porque abstrato ou porque de alguma forma 'imperial', ou seja, tratar de uma particularidade como se ela fosse universal). O unitário é a 'síntese do diverso' e o campo historicamente não tem sido considerado nessa diversidade. Por isso já há quem afirme que hoje no Brasil a construção da escola unitária passa pela Educação do campo.

Como afirmou Walter Benjamin, e penso que vale para toda esta primeira questão de compreensão da constituição originária da Educação do campo, a verdade está na tensão entre o particular e o universal. Vale então frisar/reafirmar: a Educação do campo não nasceu como defesa a algum tipo 
de particularismo, mas como provocação/afirmação desta tensão entre o particular e o universal: no pensar a transformação da sociedade, o projeto de país, a educação, a escola...16 No mesmo raciocínio talvez seja importante reafirmar também que as lutas e as práticas originárias da Educação do campo nunca defenderam ou se colocaram na perspectiva de fortalecer a contradição inventada pelo capitalismo entre campo e cidade. A questão é de reconhecer a especificidade dos processos produtivos e formadores do ser humano que acontecem no campo, compreender como historicamente essa relação foi formatada como sendo de oposição, exatamente para que se explicitem os termos sociais necessários à superação desta contradição.

\section{Sobre as tensões/contradições do percurso da Educação do campo}

É preciso considerar, como afirmei no início destas notas, que o percurso é curto e nossa capacidade de retrovisão histórica por isso é ainda pequena. Mas talvez já seja possível identificar algumas expressões importantes do movimento da realidade, particularmente nestes dez anos do 'batismo', ou seja, identificar as principais tensões e contradições constituidoras deste percurso, para tentar perceber os principais desafios do momento atual.

Destaco dois grandes focos de tensões ou de concentração das contradições: o primeiro e principal está na própria dinâmica do campo dentro da dinâmica do capitalismo e do acirramento das contradições sociais que vem do movimento de expansão do capital, brutalmente acelerado no campo nestes últimos anos. O segundo diz respeito à relação tensa (que na sociedade capitalista não tem como não ser contraditória) entre Pedagogia do Movimento e políticas públicas, relação entre movimentos sociais com projeto de transformação da sociedade e Estado.

Note-se que não se trata de contradições da Educação do campo em si mesma, ou criadas pelo seu movimento específico, mas sim as contradições que, estando presentes no contexto de sua origem, foram delineando seu percurso, ao mesmo tempo que têm sido explicitadas e mexidas por ele. Por isso não podem deixar de ser consideradas na interpretação e no debate de balanço e projeção da Educação do campo.

\section{Educação do campo e luta de classes}

O desenvolvimento da Educação do campo acontece em um momento de potencial acirramento da luta de classes no campo, motivado por uma ofensiva gigantesca do capital internacional sobre a agricultura, marcada especialmente pelo controle das empresas transnacionais sobre a produção agrícola, 
que exacerba a violência do capital e de sua lógica de expansão sobre os trabalhadores, e notadamente sobre os camponeses. 17 No caso brasileiro, podemos observar como esta lógica se realiza através de diferentes e combinados movimentos, apenas aparentemente contraditórios entre si, porque integram uma mesma lógica: expulsa trabalhadores do campo ao mesmo tempo em que promete incluí-los na modernidade tecnológica do agronegócio; subordina a todos, de alguma forma, ao modelo tecnológico que vem sendo chamado de 'agricultura industrial' e mantém seus territórios de trabalho escravo.

A ofensiva do capital no campo (talvez mais violenta na proporção da própria crise estrutural do capital) está tornando mais explícitas as contradições do sistema capitalista, contradições que são sociais, mas também ambientais e relacionadas ao futuro do planeta, da humanidade. O debate mundial que está sendo feito hoje sobre a crise alimentar é emblemático, inclusive para mostrar a relação campo e cidade. 18

O agronegócio, representação econômica e política do capital no campo, tem feito também uma ofensiva de disputa ideológica na sociedade: "Sim", dizem os 'empresários' do campo, "é preciso acabar com o latifúndio improdutivo, mas através do agronegócio, da modernização da agricultura, do campo e não da reforma agrária e dos movimentos sociais atrasados que ainda lutam por ela: é o agronegócio que vai resolver os problemas da produção de alimentos, de trazer mais divisas ao país..." Mas, por via das dúvidas, os grandes proprietários não têm ficado somente neste plano de luta: alegando que precisam de mais 'tranquilidade para trabalhar' (explorar o trabalho), têm promovido cada vez mais investidas de criminalização dos movimentos sociais, ainda que nesse contexto de enfraquecimento do polo do trabalho, dos trabalhadores, suas lutas sejam hoje muito mais de resistência do que de enfrentamento direto ao capital. Perigoso será se alguns setores da sociedade passarem a escutar os movimentos sociais, dando-se conta que a defesa do meio ambiente, por exemplo, exige o combate à lógica de produção de alimentos própria do agronegócio. Maior perigo ainda se as organizações ou os movimentos sociais aprofundarem sua atuação sobre as contradições do modelo atual, agora mais visíveis pela crise mundial do capitalismo.

A lógica de expansão do capitalismo no campo, ou a lógica de pensar o campo como lugar de negócio, não inclui, não precisa das 'escolas do campo', mas parece já estar exigindo que a questão da educação, e particularmente da educação escolar dos trabalhadores do campo, entre na (ou volte à) agenda política do país:

Primeiro, porque a chamada 'reestruturação produtiva' chegando agora ao campo requer uma mão-de-obra mais qualificada, pequena é verdade (e não estritamente formada para o trabalho agrícola em si), mas numa 
demanda que já justifica o interesse dos 'empresários rurais' em discutir formação ou educação profissional, reajustes na 'vocação' das escolas agrotécnicas, novos currículos para os cursos de agronomia, cursos superiores voltados diretamente à gestão do agronegócio.

Segundo, porque nesse contexto de 'modernização da agricultura', onde a chamada 'agricultura familiar' deve se inserir para sobreviver ("sobreviverão os melhores, os mais modernos", é a afirmação), já não parece tão ruim que estes agricultores tenham acesso à escolarização básica: espécie de 'exército de reserva' para as demandas das empresas que comandam os negócios agrícolas: mas isso sem excessos, é claro, porque afinal é sempre bom poder contar com a alternativa do trabalho escravo em alguns lugares (!) e o Estado precisa dar prioridade às demandas específicas do capital e não gastar recursos na construção de um sistema público de educação no próprio campo, que necessariamente atenderia as demandas do polo do trabalho.

Terceiro, onde afinal existirem escolas para as famílias trabalhadoras do campo, seja pela pressão dos movimentos sociais ou por concessão de empresas 'humanitárias', elas podem ser (já foram em outros tempos) um bom veículo de difusão da ideologia do agronegócio: através da nova geração 'modernizar' as mentes para a nova 'revolução verde', a dos transgênicos, da tecnologia 'terminator', da monocultura para negócio, dos insumos químicos industriais, da maquinaria agrícola pesada, completamente submetida à lógica da reprodução do capital. Em muitos estados este tipo de investida já tem se materializado em materiais didáticos ou paradidáticos produzidos pelas próprias empresas, muitas vezes com recursos públicos.

E se tudo isso puder acontecer com mais facilidade e agilidade porque hoje existe nos governos a 'pasta' da Educação do campo, "viva a Educação do campo"! Apenas é preciso tratar de afastá-la desses 'agitadores prémodernos', ou de movimentos sociais 'como o MST', que ainda continuam empunhando a bandeira da reforma agrária, da soberania alimentar e energética, da biodiversidade, do respeito ao meio ambiente...

Nesse mesmo movimento da realidade há pelo menos outros dois elementos importantes: aumentou a pressão dos movimentos sociais sobre o setor público, cobrando especialmente o direito de acesso à escolarização pública, básica e superior. Aumentou porque foram entrando novos movimentos ou grupos nessa pressão: outras organizações da Via Campesina Brasil (o Movimento dos Atingidos por Barragens - MAB, o Movimento das Mulheres Camponesas - MMC, o Movimento dos Pequenos Agricultores MPA, a Pastoral da Juventude Rural - PJR, a Comissão Pastoral da Terra CPT e a Federação dos Estudantes de Agronomia - Feab), o movimento sindical do campo (especialmente o vinculado à Confederação Nacional dos 
Trabalhadores da Agricultura - Contag e à Federação dos Trabalhadores da Agricultura Familiar - Fetraf). E aumentou porque o trabalho dos movimentos sociais e as suas conquistas destes anos, ainda que apenas de políticas focais, como o Pronera, por exemplo, ajudaram a ampliar a consciência do direito, mexer com o imaginário dos camponeses: “Pensando bem, não é verdade que nós camponeses não precisamos de estudo e que não podemos continuar estudando..." Além disso, há todo um trabalho específico com a militância, feito por alguns movimentos sociais, sobre o dever de estudar para poder compreender melhor a complexidade do momento atual da luta de classes. Por isso aumenta o número de cursos de formação, em que pese o refluxo organizativo e das lutas sociais de massa.

O outro elemento diz respeito a uma característica da sociedade brasileira que prima por discursos e documentos avançados, no plano de um ideário republicano e de uma democracia liberal, ainda que na prática os desminta a todo momento: é assim que temos, por exemplo, o ECA (Estatuto da Criança e Adolescente) há 18 anos, elogiado no mundo inteiro, e descumprido desavergonhadamente em cada esquina. É nesta mesma lógica que fica difícil afirmar publicamente que determinada parcela da população tem menos direito à educação pública do que outros. Direito universal, individual (virtual, é claro). E no caso da crítica de que veio tratando a Educação do campo nestes dez anos, há um ingrediente a mais: afinal, não fica bem para um país 'emergente' como o Brasil ter índices de analfabetismo e de acesso à educação básica que são 'puxados para baixo' por 'culpa' da população rural e, ainda pior, o governo federal nem dispor de dados estatísticos específicos desta situação e que permitam pelo menos anunciar sua disposição de ter algumas políticas nessa área. 19

Este processo, nesses e noutros aspectos que precisam ser complementados em um esforço de análise mais completa e rigorosa, talvez explique porque afinal a Educação do campo 'vingou', existe, entrou na agenda de governos, universidades, movimentos sociais; virou questão, embora não tenha se tornado política pública, e menos ainda política de Estado. Na prática, os governos têm combinado políticas focais (importantes) de ampliação do acesso à educação básica e de formação de educadores do campo com a manutenção de políticas de fechamento de escolas ou a retomada de programas alienígenas como o da Escola Ativa, por exemplo.

Algo que precisamos aprofundar em nosso debate é que a tendência de futuro, considerada a correlação de forças políticas do movimento atual, parece ser a de retrocesso ao outro polo da contradição, pelo menos do ponto de vista da política de governos: um retorno à educação rural, ou seja, de uma política sim para a educação dos trabalhadores do campo, frise-se, para eles, a serviço da nova fase do capitalismo no campo, o que significa dizer, voltada para os interesses do "avanço do capitalismo financeiro e das em- 
presas transnacionais sobre todos os aspectos da agricultura e do sistema alimentar dos países e do mundo" (Via Campesina, 2008, p. 1).

Será este então o principal balanço dos dez anos de Educação do campo: o que afinal conseguimos foi trazer de volta à agenda da política educacional do país a educação rural, que na época da primeira Conferência Nacional de Educação do campo em 1998, já tinha sido descartada como 'residual', atrasada, pelos governos neoliberais mais autênticos?

O que naquele período não era possível enxergar como hoje é que o quadro em que o debate da Educação do campo estava se inserindo era o de transição de modelos econômicos, que implicaria em um rearranjo do papel da agricultura na economia brasileira (capitalista), passando a ter um lugar de maior destaque, só que pelo polo do agronegócio e projetando uma marginalização ainda maior da agricultura camponesa, da reforma agrária, ou seja, das questões e dos respectivos sujeitos originários deste movimento. 20 Por isso alguns aliados que conseguimos em 1998 para recolocar o rural na agenda do país não são necessariamente aliados hoje na tomada de posição sobre que rural deve estar na agenda, inclusive da educação, entre o projeto do agronegócio e o projeto da agricultura camponesa, de convivência cada vez menos possível no cenário de reprodução (desenfreada ou desesperada?) do capital.

Menos ainda podíamos saber naquele momento que dez anos depois esta própria hegemonia estaria em crise e que sua primeira expressão mais explosiva diria respeito à questão dos alimentos, explicitando que a ofensiva do capital sobre a agricultura está pondo em risco a possibilidade de alimentar o grande contingente de pessoas do nosso planeta.

\section{Pedagogia do Movimento e política pública}

O segundo grande foco de tensões e contradições no percurso da Educação do campo diz respeito à relação entre Pedagogia do Movimento e política pública ou na relação entre movimentos sociais e Estado. Não é outro foco no sentido que aconteça separado do primeiro, bem ao contrário. A distinção aqui é para olhar o mesmo movimento da realidade desde um outro ângulo, relacionado aos sujeitos originários da Educação do campo.

A Educação do campo se construiu pela passagem da política produzida nos movimentos sociais para o pensar/pressionar pelo direito do conjunto dos camponeses ou dos trabalhadores do campo. Isso implicou um envolvimento mais direto com o Estado na disputa pela formulação de políticas públicas específicas para o campo, necessárias para compensar a histórica discriminação e exclusão desta população do acesso a políticas de educação, como a tantas outras. No tipo de sociedade em que vivemos, bem 
se sabe em que jogo político isso se insere, ou seja, em que correlação de forças e opção de classe se move este Estado.

A dimensão da política pública está na própria constituição originária da Educação do campo, mas sua configuração e mesmo sua centralidade foram definidas no processo, com a ampliação dos sujeitos envolvidos e das articulações políticas, e pelas novas possibilidades abertas por um governo federal como o de Lula da Silva. Não por acaso é a II Conferência Nacional de Educação do Campo de 2004 que confirma a força assumida pela luta por uma política pública de Educação do campo, através do lema aprovado pelos seus participantes: "Educação do campo: direito nosso, dever do Estado".

É importante ter presente uma sutileza que marca a Educação do campo: o MST, desde o seu início, lutou por escolas públicas, mas até o momento de entrada na Educação do campo não tinha colocado em sua agenda de debates e de lutas a questão da política pública, de pensar a educação para além de si mesmo, ou para além da esfera dos movimentos sociais, de pressionar o Estado a garantir direitos para o conjunto da população do campo, de buscar interferir, afinal, no desenho da política educacional brasileira.

O percurso da Educação do campo foi desenhando a dimensão da política pública como um dos seus pilares principais, na tensão permanente de que esta dimensão não 'engolisse' a memória e a identidade dos seus sujeitos originários, tensão tanto mais acirrada pela lógica da 'política pequena' que domina o 'gerenciamento' do Estado brasileiro, algo não de todo compreendido pelos movimentos sociais (agora talvez um pouco mais do que antes...).

Esta focalização de lutas, de articulações, de práticas, em torno da política pública vem representando ao mesmo tempo um avanço e um recuo, um alargamento e um estreitamento, radicalização e perda de radicalidade na política dos movimentos sociais do campo em relação à educação. É um 'salto de qualidade' no sentido de superação dialética do momento anterior, sobre o que de fato ainda não se tem condições objetivas (tempo histórico) de analisar com mais profundidade, mas em torno das quais já é possível arriscar algumas percepções.

Em termos ainda elementares de análise, podemos afirmar que o avanço, ou o salto de qualidade, tem a ver com a necessária articulação entre os próprios movimentos sociais, dos movimentos sociais com outras forças, outros sujeitos, materializando uma perspectiva muitas vezes defendida no ideário de cada movimento, mas difícil de concretizar, que é a de romper com corporativismos, particularismos, interesses imediatos. Isso implica em outro avanço, que é o de pensar o público recuperando o seu sentido originário de um espaço próprio aos interesses do povo, da maioria da população (e não como um lugar ou uma política subordinada a um Estado 
de classe); espaço, nesse sentido, de democratização da participação política (governo do povo). Para os movimentos sociais, lutar pela Educação do campo é passar a pensar na educação do conjunto da classe trabalhadora e é buscar pautar dessa forma, em uma perspectiva de classe, a questão da política educacional. E no específico de organizações como o MST, significa passar a compreender que a ocupação da escola pelo movimento precisa ser feita/pensada como apropriação da escola pelos trabalhadores, pelo seu projeto histórico e não apenas pelos interesses imediatos da organização, por mais justos, politizados e amplos que eles possam ser.

Entrar na disputa de forma e conteúdo de políticas públicas, como buscam fazer os sujeitos da Educação do campo, é de fato entrar em uma disputa direta e concreta dos interesses de uma classe social no espaço dominado pela outra classe, com todos os riscos (inclusive de cooptação) que isso implica, mas também com essas possibilidades de alargamento de compreensão da luta de classes e do que ela exige de quem continua acreditando na transformação mais radical da sociedade, na superação do capitalismo.

Esta é a radicalização, e nesta radicalização talvez a grande novidade histórica da Educação do campo, mas que pode implicar, já tem implicado neste percurso tão breve, em perda de radicalidade. A radicalização tem a ver, pois, com o alargamento de perspectiva: não há como construir um projeto alternativo de campo em nosso país sem ampliar as lutas, sem ampliar o leque de alianças, inclusive para além do campo; e não tem como avançar em transformações importantes sem incluir na agenda de lutas a questão da democratização do Estado, com todas ou por todas as contradições que isso encerra. E para cada movimento social em particular, não há justificativa para ocupar-se da educação, e da educação do conjunto dos trabalhadores, se não for por objetivos relacionados a lutas mais amplas.

A perda de radicalidade, por sua vez, tem a ver com concessões e estreitamentos, que também podem ser entendidos como recuos, retrocessos. Na sociedade em que estamos e numa correlação de forças tão desfavorável aos trabalhadores e à própria ideia de transformações sociais mais radicais, não se espere que o Estado brasileiro, e nem mesmo que os 'governos de plantão', aceitem (primeiro) uma política de educação que tome posição (prática) por um projeto popular de agricultura, de desenvolvimento do campo, do país, que ajude a formar os trabalhadores para lutar contra o capital e para construir outro sistema de produção, outra lógica de organização da vida social (que é exatamente o objetivo originário da Educação do campo). E (segundo) que aceitem os movimentos sociais como protagonistas da Educação do campo, que aceitem os trabalhadores pobres do campo como sujeitos da construção (forma e conteúdo) de políticas públicas, ainda que específicas para sua própria educação. Se fosse assim, a hegemonia do Estado já seria outra. 
O estreitamento que vem sendo percebido no percurso da Educação do campo é, pois, de tentativa, especialmente dos governos, de fazer uma 'assepsia' política, especialmente pelo deslocamento dos seus protagonistas originários: afinal, parecem pensar muitos gestores públicos, para que continuar ouvindo os movimentos sociais se sua bandeira já está incorporada nos discursos e documentos dos governos? É melhor que o 'sistema' cuide da Educação do campo porque já sabe como fazer isso. Ademais, os movimentos tem o 'mau costume' de politizar a educação e isso não é bom para o 'sistema'! E deslocar a centralidade dos movimentos sociais no debate da Educação do campo acaba sendo também uma forma de alterar seu conteúdo político-pedagógico de origem, buscando enfraquecer ou relativizar ao máximo uma possível influência de concepções de educação sobre outros sujeitos, notadamente sobre os educadores das escolas do campo.21

Há um outro detalhe significativo neste estreitamento: na lógica dominante de formulação de políticas públicas e mesmo do sistema educacional, política de educação só pode ser política de educação escolar. Daí a tensão permanente: para o sistema, Educação do campo trata de escolas, o que representa um recuo radical na concepção alargada de educação defendida pelos movimentos sociais, pela Pedagogia do Movimento. No âmbito das políticas, isso se tenta resolver lutando por diferentes políticas, relacionadas à produção, à cultura, à saúde. Precisa ter uma 'pasta' de Educação do campo quase em cada ministério (ou secretaria de estado) para garantir fragmentos que relembrem a visão de totalidade originária na esfera dos direitos.

Além disso, estreita-se pelo 'enquadramento': a pressão social trouxe ao debate a ideia da especificidade, mas no momento da formulação de uma política a tendência nunca é o específico (pela novidade do conteúdo) alterar a forma, mas sim o específico ter que se enquadrar na forma já instituída, ainda que seja a forma que contribuiu para a exclusão e a discriminação que justificaram a discussão da especificidade (!). Algo um pouco diferente se admite hoje em algumas políticas focais, recortadas no tempo, no espaço, nos sujeitos, mas que então não se configuram como políticas efetivamente públicas, de perspectiva universalizante.

Diga-se de passagem, estas políticas focais 22 têm sido marca do governo atual, notadamente o federal, e é preciso dizer que são importantes no jogo político, porque fazem emergir as contradições estruturais, e por isso mesmo são tão, e cada vez mais, combatidas pelas forças políticas dominantes.

Nos movimentos sociais do campo, ou pelo menos em alguns deles, esta questão das políticas públicas, ou de dar prioridade à luta pela democratização do Estado a favor dos interesses sociais dos trabalhadores, tem sido foco de tensões e motivado debates intensos. Às vezes chega a parecer para alguns que se trata de uma escolha: ou ficamos com a Educação do campo 
(entendida então como política pública) ou com a Pedagogia do Movimento, como se as contradições pudessem se resolver no plano do ideário e não da realidade; como se não houvesse circunstâncias objetivas condicionando o caminho seguido até aqui.

Nesta mesma perspectiva, já integra o percurso da Educação do campo um movimento de crítica teórica vindo de setores de esquerda, notadamente acadêmicos. Algo que precisa ser analisado com mais rigor, mas que me atrevo a dizer que em alguns casos acaba se somando às forças que buscam reviver a lógica perversa da educação rural, sem precisar brigar por esse nome (como ainda fazem alguns governos mais retrógrados como o do Rio Grande do Sul, por exemplo). Estou me referindo a dois tipos de críticas que têm aparecido em alguns textos ou exposições mais recentes, pontuais: uma a de que a Educação do campo seria politicamente conservadora por se 'misturar' com o Estado (burguês) e então não ter como portar objetivos de transformação social. E a outra de que a especificidade a condena a ser divisionista da classe trabalhadora e, pior, trabalhando com a parcela dos camponeses, só pode ser reacionária.

Estas posições, além de fortemente idealistas, parecem retomar, sem explicitar, aquela visão de 'como assim, camponeses'? Porque talvez isso de fato estranhe a muitos: como entender que um movimento social, como o MST, de base social camponesa, radicalize as lutas de enfrentamento direto ao capital e ao mesmo tempo aceite participar de debates de formulação de políticas de governo, ainda que depois não seja considerado nelas? Uma análise mais histórica das próprias transformações na luta pela reforma agrária, provocadas pela própria dinâmica contraditória do capitalismo, certamente colocaria a questão muito mais no plano dos impasses do que no da 'estranheza' ou mesmo da incoerência.

É fundamental não perdermos na trajetória da Educação do campo a centralidade da dimensão da crítica prática que somente é assegurada pelos seus sujeitos mais diretos: os trabalhadores do campo, no movimento real (contraditório) de formação de sua consciência, de construção de seu projeto, inclusive educativo. Se deslocarmos esta centralidade em nome da 'afirmação obstinada de princípios abstratos', poderemos, sem querer, estar ajudando a eliminar as contradições no plano das ideias, o que na prática significa hoje, repetindo e não repetindo a história, reforçar politicamente o polo da 'educação rural'.

\section{Sobre impasses e desafios do momento atual}

Nestas notas, penso, sobretudo, nos impasses relacionados à atuação dos movimentos sociais em relação à Educação do campo, pela importância 
atual da retomada deste protagonismo e, especialmente na relação com o Estado, do desafio de manter vivo o contraponto da Pedagogia do Movimento. Desafio que não é apenas dos próprios movimentos sociais, mas de todos os sujeitos comprometidos com o projeto político-pedagógico originário da Educação do campo, através de uma ação política articulada e não por fragmentos, como se está tendendo a fazer hoje.

Uma questão que me parece crucial para o debate dos impasses do momento atual é que estamos diante de um risco efetivo de recuo da pressão dos movimentos sociais por políticas públicas de Educação do campo, seja pelo refluxo geral das lutas de massas, e consequentemente o enfraquecimento dos movimentos sociais, acuados pela necessidade de garantir sua sobrevivência básica, seja pelo receio de 'contaminação ideológica', ou de cooptação pelo Estado, ou até pela falta de consenso sobre o papel da educação na luta de classes e neste momento histórico em particular. Entendo que este recuo seria um retrocesso histórico para a classe trabalhadora e para a história da educação brasileira.

Um recuo quantitativo e qualitativo. No meio de todas as contradições mencionadas e dos limites práticos que a correlação de forças impõe ao projeto dos trabalhadores, talvez se possa afirmar que nunca estivemos no país numa situação como a atual em relação à ampliação da noção/consciência do direito à educação entre os camponeses (pelo menos entre aqueles com alguma aproximação a organizações coletivas) e ao reconhecimento deste direito pela sociedade.

Nesse sentido, o desafio para os movimentos sociais é aumentar a pressão pela massificação das lutas para além dos trabalhadores que os integram, mostrando na prática a falácia do discurso liberal da universalização do acesso à educação. E vincular esta luta a outras lutas sociais que assumem o caráter de luta de classes, mantendo a contradição instalada.

É importante ter presente que o recuo dos movimentos sociais na luta pela educação significa uma diminuição drástica da pressão pela conquista de direitos já reconhecidos pela sociedade, pelo retorno à dimensão do direito individual, abstratamente universal, diminuindo a tensão entre o particular e o universal, entre direitos individuais e sujeitos coletivos de direitos.

O impasse tem a ver com a tendência crescente (e compreensível pela lógica da sociedade em que ainda vivemos) de fortalecer na discussão e implementação (precária) da política pública de Educação do campo a lógica do sistema em geral, pressionando pelo esvaziamento do seu conteúdo emancipatório originário e pela ampliação da dimensão regulatória, buscando de todo modo enquadrar na ordem dada demandas que são da 'contraordem'.

Esse impasse está nos movimentos sociais e no governo atual, especialmente o federal, ainda que por motivos diferentes e com um conteúdo dife- 
rente. Se a pressão dos movimentos sociais diminuir, o governo não conseguirá avançar sequer nas políticas focais e arranhar políticas públicas que lhe permitam alterar estatísticas, 'ficar bem na foto' da universalização dos direitos liberais. Porque o agronegócio pode atender suas demandas de outra forma, o que historicamente também tem incluído o uso do sistema público para formação de seus quadros (através das escolas técnicas e agrotécnicas federais, por exemplo). Tenta usar a Educação do campo a seu favor, mas não precisa de um sistema público de educação no campo para isso (até porque ele pode ser perigoso aos seus interesses, em médio prazo). Por outro lado, se os governos não tiram do foco da Educação do campo os movimentos sociais, seu protagonismo, há uma traição à lógica estrutural da política instituída e ao projeto de classe do Estado que representam. Algo que não ousam (ou nem pensam) fazer em outras áreas, tampouco ousariam nessa.

Para os movimentos sociais de projeto político mais radical, o impasse parece estar no seguinte: seu potencial de avanço 'corporativo' está em vias de esgotamento, nessa área da política educacional como em outras. E enquanto não se vislumbram mudanças mais estruturais na sociedade, seu avanço (ou sobrevivência) não pode prescindir das lutas (que podem ser mais ou menos radicais) pela democratização do Estado em favor dos trabalhadores. Não há como massificar o acesso da base social dos movimentos, e muito menos do conjunto dos camponeses, à educação básica sem a mediação hoje da Educação do campo (com este nome ou outro), na sua dimensão de política pública (plena ou parcial). E parece cada vez mais difícil avançar na formação política dos trabalhadores para compreender a realidade do capitalismo brasileiro sem uma base geral de educação anterior fornecida pela educação escolar, ainda que de conteúdo pouco emancipatório.

Por outro lado, conformar-se com a regulação do Estado parece incoerente com os objetivos políticos desses movimentos e, mais, pode ter mesmo um efeito despolitizador de sua base ou de sua militância se não houver um trabalho pedagógico adequado, uma política de formação que permita entender o que mesmo está em questão quando se faz esta relação com o Estado. E na prática, já se disse antes, não é tão simples manter-se fiel à Pedagogia do Movimento quando se tenta ser sujeito de políticas públicas numa sociedade como a nossa, ainda que se saiba que é exatamente o conteúdo da primeira que pode pressionar pela alteração da forma da segunda.

Um grande desafio para os movimentos sociais na superação desses impasses é não confundir a Educação do campo com a Pedagogia do Movimento e ao mesmo tempo não trabalhá-las em uma visão antinômica, como coisas separadas. Se os movimentos sociais entenderem a Educação do campo somente na sua dimensão de política pública e de educação escolar e 
continuarem a pressão, mas apenas pelo direito, recuando na disputa pelo conteúdo da política e pela concepção de campo e de educação, estarão abrindo mão da identidade que ajudaram a construir e estarão eliminando a contradição pelo polo da educação rural modernizada.

Por outro lado, é preciso entender que a luta pela Educação do campo não substitui a construção histórica da Pedagogia do Movimento, e da construção do projeto de educação de cada movimento social, naquele sentido alargado de uma educação vinculada a processos de luta social organizada, capaz de mexer na estrutura de valores, na visão de mundo dos camponeses, de modo que assumam a perspectiva de construção de um projeto de campo que se situe "para além do capital" (Mészáros, 2005), e que essa educação deve ser feita de forma menos tutelada e escolarizada e desde as demandas próprias da formação dos militantes da organização, mas na necessária perspectiva de classe trabalhadora unificada na luta contra o capitalismo. Se não for assim, faltará o acúmulo de radicalidade para a própria disputa do conteúdo e do destino histórico da Educação do campo.

Juntando os dois movimentos, o que se busca afinal é uma ampliação de perspectiva, necessária para alimentar lutas sociais consequentes pela transformação das condições de vida dos trabalhadores e pela projeção de relações sociais menos degradantes do ser humano.

A retomada do protagonismo dos movimentos sociais na Educação do campo é hoje um grande desafio e que passa por uma interpretação mais rigorosa e pela difusão ampliada da compreensão desse momento da luta de classes, que inclui o debate das contradições da fase atual do capitalismo e as consequências que traz para a agricultura e para a vida (ou morte) dos camponeses, bem como para o conjunto da sociedade. Estamos entrando em um período muito propício para esse debate, e a questão da produção de alimentos pode ser uma boa porta de entrada à discussão da realidade ou do 'quadro' em que nossas ações educativas se inserem. Este debate precisa ser feito com os diferentes sujeitos da Educação do campo, mas especialmente com os próprios trabalhadores e suas famílias, e com os educadores das escolas do campo.

O mesmo desafio passa pela retomada ou pelo fortalecimento do vínculo orgânico da Educação do campo (enquanto crítica, enquanto práticas e enquanto disputa política) com as lutas de resistência dos trabalhadores do campo e a construção de um projeto de agricultura que tenha outra lógica que não esta que passou a dominar o mundo, que é a da agricultura com o objetivo do negócio, fazendo dos alimentos e da terra um objeto a mais da especulação do capital financeiro, em detrimento das pessoas (Via Campesina, 2008). Esta outra lógica é hoje identificada pelo contraponto da agricultura camponesa, 23 comprometida com uma forma de produção que garanta a alimentação dos povos do mundo, de cada povo, de todas as pes- 
soas, desafiando-se também a repensar a concepção tradicional de agricultura dos próprios camponeses, agricultores familiares, trabalhadores rurais.

O vínculo da Educação do campo com o projeto da agricultura camponesa é seu 'destino de origem', mas não está dado e, ao contrário, somente será construído no enfrentamento concreto das tendências projetadas pelas contradições em que seu percurso foi constituído, potencializando as contradições da realidade social mais ampla explicitadas pelo momento de crise estrutural do capitalismo, um enfrentamento que dificilmente será protagonizado por outros sujeitos que não os movimentos sociais que hoje assumem o embate de projetos como sua ação política principal.

A inserção neste embate implica colocar na agenda política e pedagógica das lutas e das práticas de Educação do campo questões como crise alimentar, crise energética e crise financeira, soberania alimentar, reforma agrária (incluindo nela o debate da propriedade social), agroecologia de perspectiva popular, biodiversidade, direito às sementes e à água como patrimônio dos povos, cooperação agrícola, descriminalização dos movimentos sociais, direitos sociais dos camponeses e das camponesas, crianças, jovens, adultos, idosos. Trata-se de uma agenda e uma disputa que vão muito além do campo das políticas públicas, mas que não o exclui, significando nele pressão de conteúdo, concepção, especialmente no que se refere ao direito à educação, mas também de tomar parte na definição sobre que educação, destacando-se a disputa/nova elaboração sobre que formação para o trabalho no campo.

\section{Finalizando sem concluir}

Este é um debate que está em curso, buscando acompanhar o movimento da realidade que expressa. Finalizo estas notas chamando nossa atenção para o desafio político, ao mesmo tempo prático e teórico, que temos hoje em relação à Educação do campo.

Do ponto de vista da construção de uma chave metodológica de interpretação, que foi o objetivo primeiro da produção deste texto, insisto na importância de apreendermos o movimento real da crítica da educação em que se constituiu a Educação do campo, e com o cuidado de não eliminar o movimento dialético necessário: somente chegamos à realidade através de categorias, mas essas precisam ser capazes de explicá-la em sua complexidade, o que exige muitas vezes criar novas categorias. Não podemos fazer um movimento de 'encaixe' da realidade às categorias ou às teorias a qualquer custo, porque isso falseia a realidade e empobrece a teoria.

Talvez não seja pouco buscar apreender a 'novidade' (nos dias de hoje) de uma práxis que tenta negar as antinomias e constituir a radicalidade 
(de atuação política e pedagógica) entrando na jaula do tigre para apanhar suas crias (como costuma nos dizer Gaudêncio Frigotto, referindo-se a uma metáfora de Mao Tse-Tung), correndo sim o risco, e grande, de ser 'comido' pelo 'tigre', mas pelo menos não deixando de enfrentar o risco de fazer a história...

Do ponto de vista de projetar a atuação neste movimento da realidade, destaco os dois grandes desafios postos para os diferentes sujeitos que se identificam com a constituição originária da Educação do campo. O primeiro é o de intensificar a pressão por políticas públicas que garantam o acesso cada vez mais ampliado dos camponeses, do conjunto dos trabalhadores do campo, à educação. 24 É preciso disputar a agenda do Estado, é preciso "sobrecarregar o sistema" (Wallerstein, 2002, p. 220) com as demandas do polo do trabalho (demandas de acesso que são de forma e conteúdo) para que, no mínimo, as contradições apareçam com mais força.

O segundo desafio é o de radicalizar a Pedagogia do Movimento, entendendo-a fundamentalmente como um processo formativo de base dos trabalhadores que recupere sua "humanidade roubada" (Paulo Freire) e seja capaz de romper com a estrutura de valores, com a visão de mundo, que os faz reféns da lógica do capital, politizando assim a própria luta pelo direito às formas de educação consagradas pela sociedade atual e fortalecendo seu engajamento massivo nas lutas pela superação do capitalismo. Isso inclui uma dimensão grandiosa, que é a de perceber-se como sujeito da história, que é também ser sujeito de seu próprio processo de formação para se construir como tal. Nessa perspectiva, a Pedagogia do Movimento assume também uma intencionalidade educativa na direção de preparar os trabalhadores para a construção prática deste novo modelo de produção, de tecnologia, e para as novas relações sociais que poderão começar a ser produzidas nesse movimento, o que implica a reapropriação crítica de iniciativas já existentes e bem antigas, especialmente no âmbito de uma produção diversificada e comprometida com o equilíbrio ambiental e humano. 


\section{Notas}

1 Coordenadora da Unidade de Educação Superior do Instituto Técnico de Capacitação e Pesquisa da Reforma Agrária (Iterra) e integrante da equipe de coordenação pedagógica do curso de Licenciatura em Educação do Campo, parceria entre Iterra e Universidade de Brasília (UnB). Doutora em Educação pela Universidade Federal do Rio Grande do Sul. $<$ roseli@portoweb.com.br>

Correspondência: Iterra, Rua Princesa Isabel, 373, Caixa Postal 134, Veranópolis, Rio Grande do Sul, Brasil, CEP 95330-000.

2 Este texto está sendo finalizado no momento em que a Via Campesina, movimento mundial de organizações camponesas, ao divulgar os documentos finais de sua $\mathrm{V}$ Conferência Internacional, realizada em Maputo, Moçambique, de 19 a 22 de outubro de 2008, reafirma diante da crise global do sistema capitalista seu compromisso de resistência e de luta pela vida e pela agricultura camponesa, definindo a soberania alimentar e a reforma agrária genuína e integral como bandeiras de luta fundamentais para o enfrentamento da crise desde a perspectiva da classe trabalhadora. "Aqui estamos nós, camponeses e camponesas do mundo, e nos negamos a desaparecer". Soberania Alimentar já! Com a luta e a unidade dos povos! (Carta de Maputo, outubro 2008). Como a Educação do campo se moverá em relação a esta agenda política?

3 Notas elaboradas para exposição no minicurso sobre educação do campo na $31^{\text {a }}$ Reunião Anual da Anped, programação do Grupo de Trabalho Movimentos Sociais e Educação, Caxambu, 20 e 21 de outubro de 2008, e revisadas para publicação em janeiro de 2009.

4 Sobre a crítica como princípio metodológico em Marx, tomo por base especialmente a interpretação de Enguita (1993).

5 No texto "Sobre Educação do campo", de outubro de 2007, desenvolvo um pouco mais o que chamo de 'materialidade de origem' da Educação do campo.

6 Precisamos ter presente que a educação na reforma agrária, especialmente nas práticas e reflexões do Movimento dos Trabalhadores Rurais Sem Terra (MST), não pode ser vista hoje como outra coisa, mas é sim uma particularidade dentro do próprio movimento da Educação do campo; só que não é qualquer particularidade porque é justamente a sua materialidade de origem e hoje o que representa a explicitação mais forte da perspectiva de luta e de identidade de classe para a Educação do campo.

7 Para uma análise histórica da Educação rural e o que representa é importante uma retomada dos documentos principais da articulação nacional por uma Educação do campo e suas referências bibliográficas.

8 “... a crítica há de se construir sobre a base de que não existem nem o homem abstrato, nem o homem em geral, mas o homem que vive dentro de uma dada sociedade e num dado momento histórico, que está determinado pela configuração social e pelo desenvolvimento histórico concretos, independentemente de que, por sua vez, possa e deva atuar sobre eles" (Enguita, 1993, p. 79).

9 As expressões 'como assim', 'desgarrados da terra' e 'levantados do chão' se referem à indagação irônica da poesia militante de Chico Buarque de Holanda na canção 
Levantados do chão, feita para o MST, também homenageando a obra de José Saramago e a exposição Terra do fotógrafo Sebastião Salgado.

10 Aqueles que defendem a educação na perspectiva da classe trabalhadora, mas que sem vacilação acreditam ainda hoje que dizer educação é igual a dizer escola (ou que a escola é a referência necessária para pensar qualquer processo educativo mais avançado) sentem-se desconfortáveis em relação à Educação do campo. E que bom que seja assim. Porque se o do campo for entendido como um tipo específico de escola poderá justificar estragos consideráveis na educação dos trabalhadores (sentido que certamente não corresponde à visão dos próprios trabalhadores em questão).

11 Programa Nacional de Educação na Reforma Agrária, criado em 1998, no mesmo contexto de luta dos movimentos sociais que constituíram a Educação do campo.

12 Considerar que a Pedagogia do Movimento foi na origem da Educação do campo sua mediação fundamental, enquanto concepção pedagógica, de educação.

13 Desenvolvo uma reflexão sobre a Pedagogia do Movimento e sua relação com a concepção de práxis como princípio educativo no texto “Teses sobre a Pedagogia do Movimento" (2005): na concepção da 'práxis como princípio educativo' em Marx cabem diferentes matrizes pedagógicas: o trabalho, a cultura, a luta social, a organização coletiva. E seu raciocínio nos ajuda a compreender que nenhuma matriz pedagógica deve ser vista isoladamente ou deve ser absolutizada como matriz central ou única (de uma vez para sempre, a qualquer tempo e lugar); nenhuma das matrizes tem força material suficiente para dar conta sozinha da complexidade (que se revela cada vez maior) da formação humana. O ser humano se forma pela ação combinada, que às vezes é também contraditória, de diferentes matrizes pedagógicas; dependendo das circunstâncias a influência principal pode vir de uma ou de outra matriz, mas nunca a educação de uma pessoa, ou de um coletivo, será obra de um único sujeito pedagógico. É verdade que existem diferenças de natureza entre as matrizes formadoras. O trabalho é a prática social básica de constituição do ser humano (embora não a esgote) e para Marx tem centralidade na própria conformação da práxis.

14 Experiência aqui utilizada no sentido trabalhado por Thompson em suas obras, e particularmente no texto "Educação e experiência" (2002).

15 Do ponto de vista do nosso balanço projetivo da Educação do campo cabe perguntar se é essa a reflexão predominante hoje nas assim chamadas 'escolas do campo' ou como se move o debate pedagógico feito em torno delas, pelos seus diferentes sujeitos.

16 Não se confunda esta posição com a visão de um pós-modernismo que defende a eliminação do universal em favor do particular, o que é a própria expressão da armadilha ideológica do neoliberalismo: cultuo o particular matando-o como possibilidade de ser incluído no universal, já que supostamente a universalidade não mais importa...

17 Uma análise da ofensiva das empresas transnacionais sobre a agricultura, já dentro dos marcos da crise recente do capital financeiro, pode ser encontrada no texto produzido por João Pedro Stedile, do MST, para a V Conferência Internacional da Via Campesina, outubro 2008 .

18 Algumas referências para este debate específico: Stedile, maio 2008; Carvalho, julho 2007; e Christoffoli, 2008. 
19 Especialmente a partir de 2003 começaram iniciativas do governo federal para garantir levantamento de dados específicos sobre a situação educacional da população do campo. A partir de 2005, as pesquisas do Instituto Nacional de Estudos e Pesquisas Educacionais Anísio Teixeira - Inep), vinculado ao Ministério da Educação, incluem também o recorte de dados sobre escolas de assentamentos de reforma agrária.

20 É importante ter presente que a Educação do campo se desenvolve exatamente no período do capitalismo em que se consolida o predomínio do capital monetário (ou 'financeiro') que, como nos ajuda a analisar Virgínia Fontes (2008), é uma forma bastante peculiar de fusão dos diferentes tipos de capital (industrial, comercial, bancário) que traz implicações fundamentais sobre a forma das relações sociais necessárias para a reprodução do capital e que atingem, particularmente hoje, a agricultura.

21 É preciso levar em conta que a tradição pedagógica vinculada a processos sociais emancipatórios historicamente teve pouca influência sobre os educadores brasileiros, especialmente sobre os professores de escola e sobre as instituições responsáveis pela sua formação inicial. Neste sentido, não é algo pouco importante que através da Educação do campo certas reflexões e certos textos da tradição pedagógica socialista e popular sejam não apenas retomados, mas passem a ser conhecidos por educadores que de outra forma não teriam acesso a eles.

22 Políticas focais no sentido de programas específicos que se colocam na perspectiva de políticas, a exemplo hoje do Procampo (cuja ação principal é a Licenciatura em Educação do Campo) e do Programa Saberes da Terra.

${ }^{23}$ É preciso ter presente nesta discussão um aspecto que não será aprofundado neste texto, mas que integra a agenda de estudos e debates da Educação do campo: a identificação 'camponesa' indica aqui um contraponto político e econômico de lógicas de produção e de inserção social, que não se compreende sem a ressignificação ou mesmo a rediscussão do conceito de camponês que integra o debate atual sobre projetos de campo. Ou seja, a agricultura camponesa entendida como uma categoria teórica e política no contexto do confronto de projetos (agronegócio x agricultura camponesa) e não em si mesma.

24 Acesso ampliado no duplo sentido: de massificação, ampliação quantitativa e de dimensões da educação: escolarização, mas também acesso às produções culturais e a atividades diversas de formação ao longo da vida e relacionadas às diferentes matrizes de educação do ser humano. 


\section{Referências}

CALAZANS, Maria Julieta Costa. Para compreender a educação do Estado no meio rural: traços de uma trajetória. In.: THERRIEN, Jacques; DAMASCENO, Maria Nobre (Coords.). Educação e escola no campo. Campinas: Papirus, 1993, p. 15-40.

CALDART, Roseli Salete. Sobre Educação do Campo. In.: SANTOS, Clarice Aparecida dos (Org.). Campo. Políticas públicas: educação. Brasília: Incra-MDA, 2008, p. 67-86. (Por uma Educação do Campo, n. 7. Coleção).

Teses sobre a Pedagogia do Movimento. Texto inédito. Jun., 2005.

CARVALHO, Horacio Martins de. Desafios para a agroecologia como portadora de uma nova matriz tecnológica para o campesinato. Texto inédito. Jul., 2007.

CHRISTOFFOLI, Pedro Ivan. O contexto recente da luta pela terra e pela reforma agrária no Brasil e as consequências para o alcance da soberania alimentar: uma leitura a partir da Via Campesina. Texto inédito. 2008.

ENGUITA, Mariano. Trabalho, escola e ideologia: Marx e a crítica da educação. Porto Alegre: Artes Médicas, 1993.

FONTES, Virgínia. Debate sobre a crise. Notas de exposição. São Paulo, nov., 2008.

FREIRE, Paulo. Extensão ou comunicação?. 11. ed. Rio de Janeiro: Paz e Terra, 2001.
KONDER, Leandro. A dialética e o marxismo. Trabalho necessário, ano 1, n. 1, 2003.

LEFEBVRE, Henri. Para compreender o pensamento de Marx. Lisboa: Edições 79, 1981.

MÉSZÁROS, István. A educação para além do capital. São Paulo: Boitempo, 2005.

STEDILE, João Pedro. Subsídios para compreender o significado da crise alimentar mundial e brasileira. Texto inédito. Maio, 2008.

A ofensiva das empresas transnacionais sobre a agricultura. In: CONFERÊNCIA INTERNACIONAL DA VIA CAMPESINA, 5., 19-22 out., 2008, Maputo, Moçambique.

THOMPSON, Edward. Educação e experiência. In: Os românticos: a Inglaterra na era revolucionária. Rio de Janeiro: Civilização Brasileira, 2002. cap. 1.

VIA CAMPESINA. Carta de Maputo. In: CONFERÊNCIA INTERNACIONAL DA VIA CAMPESINA, 5., 19-22 out., 2008, Maputo, Moçambique.

WALLERSTEIN, Immanuel. Após o liberalismo. Petrópolis: Vozes, 2002.

Recebido em 05/12/2008

Aprovado em 20/02/2009 